\title{
Platypnea-orthodeoxia in a patient after atrial switch operation for transposition of the great arteries: Case report
}

\author{
Hildegard Tanner, MD, ${ }^{a}$ Beat Walder, MD, ${ }^{\mathrm{b}}$ Beat Kipfer, MD, ${ }^{\mathrm{c}}$ Christian Seiler, MD, ${ }^{\mathrm{a}}$ \\ Dieter Wallmann, MD, ${ }^{\mathrm{b}}$ Thierry Carrel, MD, ${ }^{\mathrm{a}}$ Paul Mohacsi, MD, ${ }^{\mathrm{a}}$ and Roger Hullin, MD, ${ }^{a}$ \\ Bern, Switzerland
}

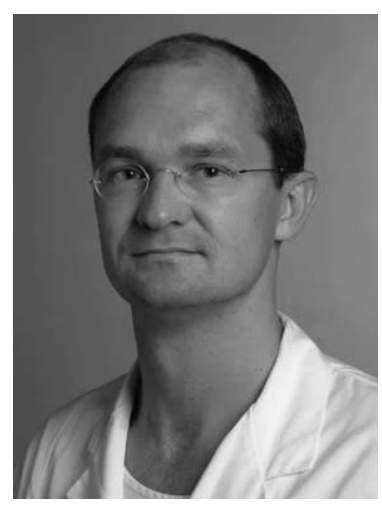

Dr Hullin
I n April 2001, a 30-year-old man was admitted to our hospital with a history of 3 days of imperative sleepiness after getting up. Weeks before, he had noted a progressively reduced exercise capacity. Nevertheless, he had worked full time as a construction craftsman until admission. At the age of 2 years, he had undergone an atrial switch operation (modified Mustard procedure) for dextrotransposition of the great arteries. Thereafter he had a normal life until the spring of 1999, when he first noticed fatigue after strenuous effort. At a routine examination in March 2001, he demonstrated normal working capacity on treadmill exercise testing.

On admission routine laboratory values, including endocrinologic parameters, were unremarkable, as were results of chest radiography, cerebral magnetic resonance imaging, electroencephalography, and polysomnography. The transthoracic echocardiography was unchanged from 1999, demonstrating a systemic right ventricle with eccentric hypertrophy and severely reduced ejection fraction (20\%). Spiroergonometry demonstrated a peak oxygen volume of $24.7 \mathrm{~mL} / \mathrm{kg} \cdot \mathrm{min}$, confirming a good physical capacity. Cardiac catheterization in supine position demonstrated the dilated systemic right ventricle $(301 \mathrm{~mL})$, with markedly reduced pump function and a moderately diminished cardiac index $\left(2.16 \mathrm{~L} /\left[\mathrm{min} \cdot \mathrm{m}^{2}\right]\right)$ but no evidence of right-to-left shunting. Pulmonary function testing revealed normal respiratory and dynamic values but slightly reduced diffusion capacity for carbon monoxide $(22.5 \mathrm{~mL} /[\mathrm{mm} \mathrm{Hg} \cdot \mathrm{min}])$.

Blood gas measurements in supine and standing positions showed substantial drops in the arterial $\mathrm{PO}_{2}$, from $75.5 \mathrm{~mm} \mathrm{Hg}$

\footnotetext{
From the Departments of Cardiology, Cardiovascular Surgery, and Pulmonology, University Hospital Bern (Inselspital), Bern, Switzerland.

Received for publication Sept 4, 2002; accepted for publication Sept 9, 2002.

Address for reprints: Roger Hullin, MD, Department of Cardiology, Swiss Cardiovascular Center Bern, University Hospital Bern, CH 3010, Bern, Switzerland (E-mail: roger.hullin@insel.ch).

J Thorac Cardiovasc Surg 2003;125:1559-60

Copyright (C) 2003 by The American Association for Thoracic Surgery $0022-5223 / 2003 \$ 30.00+0$

doi:10.1016/S0022-5223(03)00051-5
}

Table 1. Arterial blood gas analyses before and after transplantation

\begin{tabular}{|c|c|c|c|}
\hline & \multicolumn{3}{|c|}{ Bicycle } \\
\hline & Supine & (80 W, semiupright) & Upright \\
\hline \multicolumn{4}{|c|}{ Before heart transplantation } \\
\hline $\mathrm{P}_{2}(\mathrm{~mm} \mathrm{Hg})$ & 75.5 & 69.4 & 59.9 \\
\hline Oxygen saturation (\%) & 96 & 94 & 92 \\
\hline $\mathrm{PCO}_{2}(\mathrm{~mm} \mathrm{Hg})$ & 36.2 & 33.8 & 31.8 \\
\hline \multicolumn{4}{|l|}{ After heart transplantation } \\
\hline $\mathrm{P}_{2}(\mathrm{~mm} \mathrm{Hg})$ & 79.9 & 79.8 & 87.8 \\
\hline Oxygen saturation (\%) & 96 & 95 & 97 \\
\hline $\mathrm{PcO}_{2}(\mathrm{~mm} \mathrm{Hg})$ & 38.0 & 33.6 & 37.0 \\
\hline
\end{tabular}

supine to $59.9 \mathrm{~mm} \mathrm{Hg}$ standing, and $\mathrm{PCO}_{2}$, from $36.2 \mathrm{~mm} \mathrm{Hg}$ supine to $31.8 \mathrm{~mm} \mathrm{Hg}$ standing (Table 1). During a 5-minute stationary bike exercise in a semierect position, hypoxemia was minimal (Table 1). Thus the clinical diagnosis of platypnea-orthodeoxia $^{1}$ was made.

Platypnea-orthodeoxia is a rare clinical entity with the unusual symptom of dyspnea related to arterial deoxygenation induced by upright position and relieved by recumbency. In patients without previous cardiac surgery, hypothetic explanations for right-to-left shunting in the upright position have been related to redistribution of blood flow caused by unequal compliance between diseased ventricles or distortion of the fossa ovalis and the atria. ${ }^{1}$ In our patient, transesophageal Doppler echocardiography revealed a 4-mm wide baffle leak in the intra-atrial tunnel adjacent to the superior vena cava (Figure 1A). In the supine position there was a left-to-right shunt across the discontinuity (Figure 1B); however, assumption of the upright position or release of Valsalva maneuver induced an increased right-to-left shunt responsible for orthodeoxia (Figure 1C). A recent retrospective study revealed occurrence of baffle leaks in $27.5 \%$ of patients after atrial switch operation for dextrotransposition of the great arteries. ${ }^{2}$ So far, hypoxemia but not orthodeoxia after atrial switch operations has been described in the literature. ${ }^{3}$

Today, percutaneous closure has become the accepted treatment of choice in platypnea-orthodeoxia associated with a patent foramen ovale ${ }^{1}$ and has already been performed successfully in single cases of baffle leaks. ${ }^{4}$ In our patient interventional as well as 

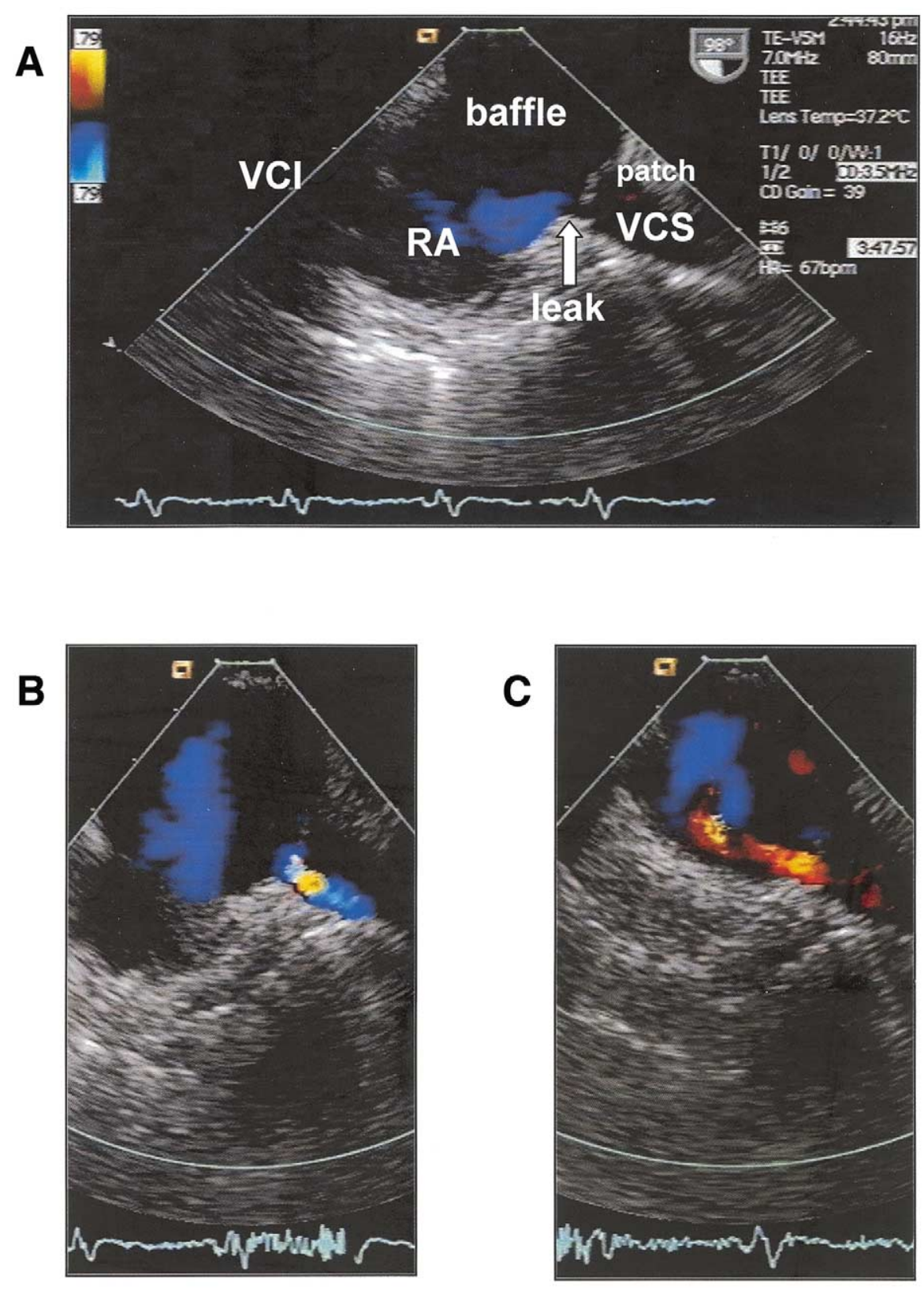

Figure 1. Transesophageal echocardiograms. A, Pathoanatomic survey. VCI, Inferior vena cava; VCS, superior vena cava, $R A$, right atrium. $B$, Left-to-right shunt in supine position. $C$, Right-to-left shunt in upright position.

operative closure of the atrial baffle were not considered because of expected high risks in view of the severely reduced right ventricular pump function. In the following months, the patient's symptoms increased, so cardiac transplantation was performed. Thereafter orthodeoxia-related symptoms disappeared, and the patient returned to work.

\section{References}

1. Wahl A, Windecker S, Meier B. Patent foramen ovale: pathophysiology and therapeutic options in symptomatic patients. Minerva Cardioangiol. 2001;49:403-11.
2. Peters B, Abdul-Khaliq H, Lange PE. Late complications following early childhood atrial switch operations for D-transposition of the great arteries. Incidence, diagnosis and therapy. Dtsch Med Wochenschr. 2001;126:1037-42.

3. Wildevuur CR, Bergstra A, Jager JN, Kuipers JR, Mook GA, van der Heide JN. Unusual complication after total correction of transposition of the great arteries. A case report. J Cardiovasc Surg. 1975;70:471-7.

4. Schneider DJ, Moore JW. Transcatheter treatment of IVC channel obstruction and baffle leak after Mustard procedure for D-transposition of the great arteries using Amplatzer ASD device and multiple stents. J Invasive Cardiol. 2001;13:306-9. 